\title{
REGIONALISMO, ECONOMÍA POLÍTICA Y GEOPOLÍTICA: TENSIONES Y DESAFÍOS EN LA NUEVA BÚSQUEDA DE INSERCIÓN INTERNACIONAL DEL MERCOSUR
}

Regionalism, political economy and geopolitics: tensions and challenges in the new search of international insertion of Mercosur

\author{
Nicolás Pose \\ Departamento de Ciencia Política - Facultad de Ciencias Sociales \\ Universidad de la República \\ nicolas.pose@cienciassociales.edu.uy \\ https://orcid.org/0000-0002-4462-1189 \\ Lincoln Bizzozero \\ Unidad Multidisciplinaria - Facultad de Ciencias Sociales \\ Universidad de la República \\ lbizzozero@gmail.com \\ https://orcid.org/0000-0001-9367-1695
}

Recibido: $11 / 10 / 2018$

Aceptado: 22/02/2019

\begin{abstract}
Resumen: El Mercosur se encuentra en una etapa de cambios. El énfasis político, característico de la década pasada, ha sido reemplazado por una agenda que prioriza la inserción externa del bloque. En este marco, las principales alternativas, no necesariamente excluyentes, son: una Atlántica, centrada en la Unión Europea; y otra centrada en Asia-Pacífico. Este artículo asume que la evolución del regionalismo y las opciones políticas se encuentran afectadas por factores condicionantes sistémicos, geopolíticos (orientación geográfica tradicional de la inserción) y de economía política (intereses, instituciones e ideas). Sobre esta base se analizan las potencialidades, límites y desafíos de ambas alternativas, mediante el estudio de la evolución del Mercosur y de las relaciones comerciales de Argentina y Brasil con Europa y Asia.
\end{abstract}

Palabras clave: Mercosur; regionalismo; inserción internacional; acuerdos comerciales; economía política; geopolítica. 


\begin{abstract}
Mercosur is entering in a new phase of changes. The political emphasis, characteristic of the last decade, has been replaced by an agenda that prioritizes the bloc's external insertion. In this framework, the main alternatives, not necessarily excluding, are: one Atlantic centered in the European Union; and another centered in the Asia-Pacific space. This article assumes that the evolution of regionalism and the political choices it faces are affected by systemic, geopolitical (traditional geographical orientation of the insertion) and political economy (interests, institutions and ideas) conditioning factors. Over this assumption the potential, limits and challenges of both alternatives are analyzed, through the study of the evolution of Mercosur and the trade relationships of Argentina and Brazil with Europe and Asia.
\end{abstract}

Keywords: Mercosur; regionalism; international insertion; trade agreements; political economy, geopolitics. 


\section{Introducción}

El regionalismo en América del Sur, y su expresión en materia de integración regional más importante, el Mercosur, se adentran nuevamente en una etapa de cambios. En la creación del bloque a inicios de la década de los noventa primó la agenda de liberalización comercial interna como marco desde el cual insertarse en el proceso de globalización económica, al amparo de las ideas del regionalismo abierto y el Consenso de Washington. Y siguiendo este rumbo, a mediados de la década la opción de inserción atlántica, en un eventual triángulo comercial conformado por acuerdos con Estados Unidos y la Unión Europea (UE), guio la orientación de la política externa. En cambio, en la primera década de los 2000, la construcción de una agenda de integración continental y cooperación política autónoma primó por sobre los imperativos de inserción comercial. Pero al entrar en la segunda década del siglo xxi, la evolución del Mercosur se encuentra nuevamente frente a un nuevo escenario.

Ni la orientación ni los alcances de este cambio están aún del todo definidos, y las discusiones sobre si se está frente a un retorno de políticas anteriores o ante nuevas construcciones de política abundan en el debate político y académico (Briceño-Ruiz 2018). No obstante, y más allá de estos aspectos, lo cierto es que los cambios en la orientación política de los gobiernos en Argentina y Brasil, sumado a un conjunto de transformaciones estructurales que serán discutidas a lo largo del texto, han llevado a que el Mercosur haya relegado a un segundo plano las instancias de construcción de instituciones políticas regionales autónomas y muestre en cambio un renovado impulso en su agenda de inserción internacional y vinculación con los mercados mundiales.

Este trabajo toma como punto de partida que la evolución de los regionalismos y las instancias concretas de integración regional están signadas por condicionantes sistémicos, geopolíticos y de economía política. Y sobre esta base, se propone repasar los principales cambios en las prioridades políticas y en las orientaciones del Mercosur desde su creación, para luego centrarse en el análisis de las principales alternativas de inserción externa que actualmente circulan en la agenda (no excluyentes entre sí): una Atlántica, construida en torno a la eventual conclusión de un acuerdo con la UE, y otra que privilegia el espacio Asia-Pacífico. El objetivo consiste en identificar las potencialidades, los desafíos y los límites que envuelven cada una de ellas, a la luz de los condicionantes planteados.

El foco del trabajo será puesto en las dinámicas de interacción con terceros actores de Argentina y Brasil. Esto se debe a que el eje argentino-brasileño, y en particular sus dinámicas de cooperación y conflicto, ha sido el factor determinante por excelencia en la construcción de instancias regionales y en la adopción 
de sus orientaciones (Mera, 2005), lo que se observa en los distintos episodios históricos de aproximación e integración en la región, y se fundamenta en indicadores objetivos, tales como tamaño de sus territorios, población y volúmenes de producción económica. Justificado este recorte, se desarrollan en primer lugar los condicionantes sistémicos, geopolíticos y de economía política planteados, para luego repasar el caso concreto del Mercosur. Tras esto, se analizan las implicancias de las alternativas Atlántica y Pacífica mencionadas y, por último, se presentan unas reflexiones finales.

\section{Condicionantes geopolíticos, de economía política y sistémicas en la construcción del regionalismo: nociones generales}

Este trabajo parte del supuesto de que la construcción de regionalismos, así como de los contenidos que adquieren a lo largo del tiempo - tanto en materia de encadenamiento con fenómenos más amplios como la globalización económica o de construcción de esferas de autonomía, como de dirección de las relaciones con otros países y regiones del mundo-, no ocurren en el vacío. Por el contrario, se encuentran signadas por condicionantes geopolíticos y de economía política, los cuales a su vez operan dentro del marco más general de condiciones que vienen determinadas por la evolución de la estructura del sistema internacional.

Los condicionantes geopolíticos son construcciones que se imbrican con el surgimiento de cada Estado y que sustentan el denominado interés nacional. Las bases de un Estado, entonces, tienen que ver con ese ADN en el que surgen en el sistema internacional (Moïsi, 2008). Esa especificidad en el nacimiento del Estado es un condicionante en sí a la hora de definir la política exterior y de plantear las prioridades en relación con el entorno regional y el sistema internacional. La inserción internacional de un país no escapa a la marca del nacimiento y a la visión que se tiene sobre el papel del país en el propio sistema.

Esta construcción de la visión del país y de cómo se visualiza la geopolítica en función del momento que atraviesa el sistema internacional se va modificando a lo largo de la historia del Estado. Sin embargo, el núcleo fundamental vinculado a la posición que tiene el país en el sistema internacional y regional condiciona la visión mundo de las élites políticas y de la burocracia estatal (Florian, 2014). Esto se debe, en parte, a que las orientaciones geopolíticas que condicionan los inicios de la vida nacional, al propiciar corrientes y flujos tanto económicos como humanos, refuerzan con el paso del tiempo las prioridades de la inserción internacional. 
Y al mismo tiempo, dentro de este marco de restricciones, las decisiones son modeladas por los factores identificados por la economía política internacional: intereses, instituciones e ideas. En el primer caso, la literatura destaca la influencia de los grupos de interés, quienes de acuerdo con su posición en la estructura de la economía internacional y de las opciones de política en disputa se plantean influir en los decisores con miras a maximizar sus intereses materiales (Lake, 2009). En tanto que dentro de este enfoque, se visualiza a las instituciones como variables intervinientes que impactan en la manera en que los intereses son agregados y, por tanto, en su capacidad de influir en las políticas.

Una segunda perspectiva de las instituciones es la que pone el foco en el Estado, el cual se afirma que ejerce un efecto independiente sobre las políticas producto de prácticas burocráticas institucionalizadas y del path dependence. Finalmente, un tercer enfoque considera al rol de las ideas, las que pueden influir en las decisiones mediante su alojamiento en las propias instituciones del Estado (Hall, 1993), a través de emprendedores políticos (Rodrik, 2014) o de profesionales socializados en distintas creencias que una vez en posiciones de poder actúan conforme a ellas (Chwieroth, 2007), e incluso influyen en la forma que los grupos de interés definen dónde residen sus propios intereses materiales (Blyth, 2003; Woll, 2008).

El nuevo regionalismo, desde el cual nace el Mercosur, no puede entenderse a su vez sin referencias al contexto internacional en el que surgió. Esto es, con el ingreso del sistema internacional a una nueva etapa de globalización con posterioridad a la disolución de la Unión Soviética, se reconfiguraron los espacios regionales y con ello la articulación del ordenador mundial (Hettne, 1994). El impulso a la conformación de nuevos regionalismos como respuestas a los requerimientos del sistema para una inserción internacional provino necesariamente de los centros desarrollados (Estados Unidos, la UE y Japón), únicos capaces en ese momento de impulsar y articular los regionalismos en la globalización, generando un efecto de arrastre en la periferia.

Sin embargo, la primera década de los 2000 trajo cambios importantes que modificaron la estructura sobre la que operan los regionalismos. En el caso de Estados Unidos, principal ordenador del sistema internacional, se verificó un cambio de prioridades global a partir de los atentados del 11 de setiembre de 2001, tras los cuales su política exterior se enfocó de forma primaria en sus incursiones militares en el Medio Oriente. Y al mismo tiempo, a nivel regional, dinámicas específicas que serán revisadas más adelante hicieron, en combinación con lo anterior, que el sur de América Latina descendiera del orden de prioridades en la agenda de política exterior estadounidense (Serbin, 2010). 
Durante los inicios de los 2000 la ue concretó importantes pasos en materia de integración monetaria, dotando a un conjunto de países con una moneda común que eventualmente pudiera desafiar el estatus del dólar como principal moneda de reserva internacional (Portes y Rey, 1998), pero en materia de política exterior los avances comunitarios fueron menos ambiciosos. Y la política comercial, carta de presentación exterior por excelencia del bloque, privilegió la truncada esfera multilateral, al menos hasta el 2004, cuando culminó el mandato de Pascal Lamy como Comisario de la Comisión Europea para asuntos de Comercio (De Ville y Siles-Brugge, 2018).

La crisis financiera y económica global, iniciada en 2008 en Estados Unidos pero con consecuencias aún más profundas en la eurozona, profundizó la tendencia previa de retracción de estos ordenadores mundiales. Al mismo tiempo, allanó el camino para la aparición de nuevos jugadores globales, entre los cuales se destacaron los BRICs ${ }^{1}$ en general y China en particular. Es que el gigante asiático acumuló décadas de crecimiento económico sostenido a tasas excepcionales, lo que le permitió pasar de representar una porción ínfima en el comercio y la producción mundial a ocupar el primer y segundo puesto en estas variables, respectivamente, en tan solo 35 años.

Al ritmo de la nueva demanda por materias primas para alimentar la creciente producción asiática, se produjo también el llamado boom de las commodities. Esto significó un aumento extraordinario en los ingresos derivados de la producción de bienes primarios, que benefició tanto a los países exportadores de minerales como a los de alimentos. Tan es así, que para estos últimos significó un cambio en la tendencia de deterioro de la relación de términos de intercambio que históricamente enfrentaron (Buxedas, 2017). Estas transformaciones afectaron positivamente a los países periféricos y en desarrollo, quienes presentan en general una especialización comercial en estos sectores.

Al mismo tiempo, distintas condicionantes financieras se conjugaron para ofrecer a estos países un escenario de acceso al financiamiento internacional dotado de una gran oferta y a costos ínfimos en perspectiva histórica. Es que, por un lado, las políticas de quantitative easing de los principales bancos centrales del mundo llevaron las tasas de interés a mínimos históricos, y por el otro, la entrada de nuevos jugadores, como China, al selecto grupo de financiadores internacionales, amplió la oferta para alcanzar incluso a los sospechosos habituales de los prestamistas tradicionales (Gallagher, Irwin y Koleski, 2012). Combinados, todos estos elementos contribuyeron al ensanchamiento del espacio para generar respuestas con mayores niveles de autonomía desde los regionalismos periféricos. 
Sin embargo, entrada la segunda mitad de la década del 2010 las condiciones externas cambiaron: los precios de las commodities entraron nuevamente un uno de sus ciclos característicos de volatilidad (Buxedas, 2017) y las condiciones de financiamiento internacional, en un momento donde las tendencias hacia tomar posiciones deficitarias en materia fiscal y de cuenta corriente se volvieron más fuertes, comenzaron a endurecerse. Al mismo tiempo, deben atenderse los efectos de la profundización de la especialización productiva durante el ciclo del boom, en el que los poseedores de las ventajas comparativas tradicionales vieron fortalecida su posición, con efectos diversos en las economías políticas domésticas producto de las variaciones observadas en materia de especialización y relaciones de propiedad. En este marco de condicionantes generales, es que deben entenderse y evaluarse las alternativas actuales que enfrenta el Mercosur.

\section{El caso del Mercosur}

En el caso del Mercosur, los antecedentes inmediatos a la conformación de esta iniciativa regional muestran la superación de la histórica rivalidad argentino-brasileña, a través del Programa de Integración y Cooperación Argentino-Brasileño (PICAB) en 1986 y con medidas de confianza mutua en el campo nuclear, que sentaron las bases políticas para el nuevo regionalismo. ${ }^{2}$ La superación del conflicto argentino-brasileño posibilitó trascender la visión geopolítica de la frontera peligrosa que dominó la formulación de las políticas fronterizas y regionales por décadas. $\mathrm{Y}$ es que hasta ese momento los condicionantes geopolíticos de ambos países tenían que ver con la salida atlántica (comunicaciones con los países del Norte) y el aseguramiento de las fronteras con los países de la región.

El denominado nuevo regionalismo tuvo como referente ideacional al Consenso de Washington, guía para los gobiernos de orientación liberal que crearon el Mercosur en 1991. Un componente se orientaba a la liberalización del comercio exterior, y en este marco el Mercosur fue concebido como una plataforma de liberalización intrarregional a partir de la cual abrirse al resto del mundo, de forma consistente con el paradigma del regionalismo abierto (Bizzozero, 2008; Briceño-Ruiz, 2013). De todos modos, las ideas encuentran en ocasiones adaptaciones en sus viajes de llegada a países y regiones (Ban, 2016), y el Mercosur fue un caso de esta clase: por ejemplo, el sector automotriz, industria clave para las dos principales economías, fue regulado a través de un acuerdo de comercio administrado paralelo. Y es que en líneas más generales, la complejidad de las estructuras

2 Un antecedente clave, en tiempos autoritarios, lo constituye el acuerdo tripartito de 1979 (junto con Paraguay) para la integración en infraestructura hidroeléctrica. 
productivas y en particular los desafíos de la industria, especialmente en Brasil, pero también en Argentina, requerían de este tipo de adaptaciones para mantener su viabilidad en el marco más general de estas reformas de carácter liberal.

Pero además, al tratarse de Estados como el de Brasil, de tamaño continental, y en menor medida de Argentina (octavo país del mundo en extensión), los condicionantes geopolíticos son relevantes a los efectos de comprender la orientación y prioridades de las políticas exteriores de ambos países. Como ya se ha señalado, puesto que el eje argentino-brasileño es la base del Mercosur - y en buena medida del regionalismo sudamericano - se entiende que los condicionantes que afectan a esos países terminan condicionando la visión del bloque regional, así como la priorización de determinados países o regiones por sobre otros a la hora de promover las relaciones externas del bloque.

En los inicios del Mercosur la orientación de las políticas exteriores de Argentina y Brasil convergieron en una inserción internacional prioritariamente atlántica con foco en Estados Unidos y la UE. Las negociaciones en el marco del Acuerdo de Libre Comercio de las Américas (ALCA) y en el Acuerdo Marco Interregional con la UE daban cuenta de un posible triángulo occidental. Brasil - $\mathrm{y}$ en menor medida Argentina- estructuraban la orientación atlántica del espacio sudamericano. Esto les daba a ambos países en este eje de competencia-cooperación (superado el eje competencia-conflicto) la posibilidad de ganancias en el marco de la nueva configuración mundial-regional-nacional, a través de regímenes que aseguraran la gobernabilidad (gobernanza en el nuevo léxico) y generaban señales de legitimación de sus programas de reforma económica. A su vez, la lógica triangular interactuaba con las negociaciones a nivel multilateral, generando un complejo panorama de geoeconomía (Bouzas, 1996; Grandi, 2000).

Sin embargo, esta estrategia pronto encontró sus límites. En materia comercial, tras la conclusión de la Ronda Uruguay, tanto Estados Unidos como la UE comenzaron a demandar nuevas armonizaciones regulatorias en distintas áreas relacionadas con el comercio (temas de Singapur), las que percibían como barreras no tradicionales al acceso a mercados. Pero esta agenda encontró una amplia resistencia en los países en desarrollo, que la vieron como una amenaza hacia su espacio para aplicar políticas de transformación productiva al estilo de las implementadas por los países de desarrollo tardío (Gallagher, 2007). Y al mismo tiempo, el propio eje transatlántico encontró profundas dificultades a la hora de alcanzar un acuerdo en materia de agricultura, lo que a su vez redundó en el bloqueo general del tema a nivel multilateral, exacerbando a los países en desarrollo que tienen fuertes intereses (en muchos casos ofensivos) en la materia. En ambos planos, articulando las posiciones ofensivas y defensivas en el marco del G-20 comercio, Brasil (junto con India) tuvo un rol principal (Narlikar y Tussie, 2004). 
El siglo xxI deparó cambios en la política internacional estadounidense y en las prioridades del espacio territorial a salvaguardar. La definición de prioridades desatendió el espacio latinoamericano en las cuestiones económico-comerciales, sobre todo después de que el ALCA se terminó políticamente como propuesta en la Cumbre de Mar del Plata en el 2005. Y es que el traslado de los debates comerciales multilaterales a la esfera interamericana, sumado a la llegada de gobiernos ubicados del centro a la izquierda del espectro ideológico en las principales economías (Argentina, el propio Brasil y Venezuela), determinó el fracaso de la propuesta. De esta manera, durante más de una década el regionalismo latinoamericano fue construyendo una agenda regional propia, una institucionalidad incipiente y una nueva base de ideas.

Los países del Mercosur, con los cambios de gobierno, cuestionaron el modelo neoliberal y el paquete de ideas que conllevaba, incluyendo el regionalismo abierto en su versión original. La versión del regionalismo posliberal (Sanahuja, 2009) o poshegemónico (Riggirozzi y Tussie, 2012) o bien el continental (Bizzozero, 2014) en sentido asertivo fueron el componente de regionalismo del siglo XXI. La geopolítica se reorientó hacia bases continentales, de forma que priorizó el espacio regional sudamericano - y en menor medida el latinoamericano. La expresión institucional - y en ideas - de esta evolución fueron la Unión de Naciones Sudamericana (Unasur) y la Comunidad de Estados Latinoamericanos y Caribeños (Celac). ${ }^{3}$

En esta nueva etapa del regionalismo en América Latina signada por el boom de las commodities y la reorientación de prioridades de Estados Unidos, se dio primacía a los contenidos políticos, quedando la inserción internacional sujeta a las prioridades políticas y sociales del regionalismo en construcción. La orientación sur-sur de las políticas exteriores y la convergencia en materia de cooperación fueron los ejes que definieron las propuestas temáticas generales (Briceño-Ruiz y Morales, 2017).

Aunque históricamente América del Sur había tenido instancias de convergencia y ámbitos para analizar los temas de la región, nunca se habían generado espacios para que los asuntos internos pudieran ser canalizados vía construcciones regionales propias. Esto posibilitó que, por primera, vez el sistema burocrático político-estatal comenzara a ver los condicionantes geopolíticos fuera de la región. Las fronteras comenzaron a ser visualizadas como espacio de cooperación y problemas para el desarrollo. Y las cuestiones de seguridad atinentes a la frontera se comenzaron a pensar como cuestiones que requerían la cooperación

3 Una interpretación alternativa sugiere que estos cambios, antes que nada, tuvieron que ver con la evolución de un nuevo consenso acerca del rol del Estado, y el concomitante uso del regionalismo para avanzar esta agenda (Petersen y Schulz, 2018). Sin cuestionar esta afirmación, a efectos de este trabajo interesa destacar la reorientación y priorización geográfica de la acción regional. 
intrarregional como forma de responder a los desafíos transnacionales (Giacalone, 2015; Pereira, 2011).

Si bien hay ambigüedades en el proceso durante más de una década, entre el 2000 y el 2015 convergieron tres procesos a partir de la política internacional de Brasil: su emergencia como potencial actor global en el sistema; la construcción de un espacio latinoamericano como ámbito para la gobernanza regional y la cooperación internacional; la conformación de un espacio de paz, cooperación, desarrollo y libre comercio en América del Sur. Estos tres sucedieron convergentemente con tensiones, conflictos y contradicciones, aunque se constata una acumulación incremental en términos institucionales y en propuestas temáticas e ideas (Bizzozero, 2014).

Sin embargo, también es preciso notar que los avances en los tres planos fueron muy desiguales. En concreto, mientras que Brasil avanzó en su agenda global y la región creó espacios de gobernanza política regionales de carácter inédito, en el plano económico-productivo-comercial los progresos fueron mucho más endebles, ya que la integración productiva dependió casi en exclusivo de un instrumento de financiamiento nacional como el Banco Nacional de Desenvolvimento Econômico e Social (BNDES), no hubo coordinación macroeconómica, y la integración comercial se vio dificultada por distintas barreras y concepciones sobre los modelos a implementar.

Esto fue patente en el caso del Mercosur, en donde los avances en el plano de la construcción de nuevas instituciones políticas y la apuesta por dispositivos de carácter social contrastan con los escasos avances registrados en materia de integración productiva y comercial (Caetano, 2017). Si a esto se le agrega el problema de las promesas vacías, esto es, la adopción de normas que luego no son internalizadas por los Estados miembro y, por tanto, no entran en vigor (Arnold, 2017), entonces la imagen que se obtiene sobre los avances de la década es mucho más matizada.

Posteriormente, si bien la acumulación previa mencionada no se diluyó por completo, la crisis en Brasil cortó por el momento esta línea en la construcción de respuestas regionales. A su vez, el nuevo gobierno - transitorio y con bases de legitimidad frágiles - redefinió las prioridades temáticas y los objetivos de política exterior. Hay varios factores que podrían ser considerados para explicar esta evolución política y económico-social en este país, asunto merecedor de un examen profundo que no se pretende desarrollar aquí. Lo que interese señalar es que uno de los temas (y factores) que están produciendo una división en el sistema político brasileño es el corrimiento hacia el Pacífico del crecimiento económico a nivel internacional. En el espacio sudamericano, la Alianza del Pacífico, 
que surgió como una plataforma para el megaespacio Pacífico en construcción que impulsaba Estados Unidos, fue uno más de los factores de división entre dos miradas políticas del espectro brasileño con relación a cómo posicionar a Brasil en el frente externo. Estas dos miradas se plasmaron en las elecciones de Brasil en los debates electorales que finalmente dieron la victoria a Dilma Rousseff (Bizzozero, 2015).

El gobierno actual de Michel Temer en Brasil y el de Mauricio Macri en Argentina han replanteado la inserción internacional de los países como prioridad en el marco de la articulación con la globalización económica, lo que de alguna forma dialoga con la postura (de al menos parte) del gobierno uruguayo. Y ambos presidentes han coincidido, además, en suspender su membresía de Unasur, así como en sus posiciones frente a la situación de Venezuela. De esta manera, el regionalismo pasó de nuevo a tener un fuerte componente internacional en la construcción de la agenda regional, en oposición a la década previa. El cambio tiene un evidente motivo político e incluso coyuntural, asociado al giro electoral en Argentina y a la destitución de Rousseff en Brasil. Pero además, involucra virajes de más largo aliento, en el ámbito de los intereses económicos domésticos y de los paradigmas de ideas que orientan las políticas exteriores económicas.

En el primer caso, los sectores agroexportadores vieron fortalecida su posición tras los años del boom de las commodities. Y como contracara, los sectores industriales se han visto perjudicados por el incremento de las importaciones de productos manufacturados de China, tanto en los mercados nacionales como regionales, las que han erosionado sus posiciones previas en materia de cuotas de mercado (Gallagher y Porzecanski, 2010; Bizzozero y Raggio, 2016). El estancamiento económico actual, la caída del precio de las commodities y las presiones en materia fiscal, que actualmente enfrentan los países, no han hecho más que poner de relieve las tensiones productivas entre una especialización agroexportadora y un sector industrial que se fueron incubando en la década previa.

Pero además, en el plano de las ideas, la representación de estos intereses comenzó a cuestionar los efectos del Consenso de Beijing (Svampa, 2013; Slipak, 2014). Y de forma aún más importante, las propias cúpulas industriales brasileñas han experimentado, en este nuevo marco de incertidumbre, con adoptar un nuevo paradigma de políticas de corte liberal, tal como lo reflejan los pronunciamientos de la Confederación Nacional de Industria (CNI) desde 2013 (ej. CNI 2014; CNI 2017; Darós 2017). Estas transformaciones se entrecruzan a la vez con las tradicionales disputas entre neodesarrollistas y neoliberales a nivel de las élites políticas y burocráticas brasileñas y argentinas, y se solapan con el debate sobre orientaciones de política exterior entre los atlantistas continentales, la vertiente Pacífico-Mundo y los promotores de la orientación Sur-Sur, así como con los 
debates entre regionalistas y globalistas sobre el papel a jugar en el mundo, en particular en el caso de Brasil (Bizzozero, 2015; López y Tarciano Silva, 2015). En este marco, entonces, es que cabe analizar las alternativas pacífica y atlántica que circulan en los debates sobre la inserción internacional del Mercosur. ${ }^{4}$

\subsection{Límites geopolíticos y de economía política de la inserción en la cuenca del Pacífico}

Los miembros fundadores del Mercosur han sido históricamente países atlánticos y periféricos. Su posición geográfica, y la historia de inmigración europea, han favorecido que haya una interdependencia económica, política y social con los países europeos. Por tanto, las transformaciones experimentadas en las últimas décadas con los avances en materia de trasporte y comunicación, y el progresivo desplazamiento del motor económico del sistema internacional desde el Atlántico hacia el Pacífico, han puesto en tensión la histórica orientación geopolítica de los países del bloque.

En este sentido, el surgimiento de la Alianza del Pacífico juega un papel de interpelación al atlantismo (y también al regionalismo durante la primera década del siglo XXI) que ha guiado a los países del Mercosur. Esto se debe a que presenta una alternativa que lleva a un reexamen en múltiples dimensiones: costos y beneficios económicos para grupos domésticos, implicancias para la construcción de espacios regionales de construcción de liderazgo y plataformas políticas, e incluso un paradigma ideacional alternativo, que retoma los principios del regionalismo abierto y propone políticas de corte liberal, donde el libre comercio y la movilidad de capitales son ejes centrales.

En materia de orientación, la Alianza del Pacífico exhibe una clara propuesta de privilegiar el espacio Asia-Pacífico, en tanto nuevo epicentro económico-comercial mundial, y se presenta a sí misma como la puerta de entrada a esta región. Sin embargo, Asia-Pacífico se compone de múltiples unidades nacionales y regionales, que varían significativamente en materia de modelos económicos y políticas comerciales, así como en las alianzas económicas y políticas que privilegian en el ámbito internacional. Y, de forma crucial, también divergen en cuanto a la relevancia económica que suponen para los países del Mercosur.

La información presentada en los gráficos 1 y 2 busca ilustrar esta diferencia. Pues mientras China representa casi el $20 \%$ del total de las exportaciones

4 Un debate paralelo y de importancia medular y creciente, pero que escapa al alcance de este trabajo, viene dado por la alternativa de flexibilizar el bloque para habilitar la negociación individual de acuerdos comerciales con terceros. 
brasileñas, y el $7 \%$ de las exportaciones argentinas, la segunda mayor economía asiática, Japón, no llega al 3 \% para ninguno de los casos. En tanto que la tercera, Corea, no llega a representar siquiera el $2 \%$ del total de la canasta exportadora de ambos países. Tan solo el grupo de la ASEAN, conformado por 10 economías asiáticas, ${ }^{5}$ se ubica al nivel de China para el caso de Argentina, hecho que no se repite para el caso brasileño, en donde el bloque en su conjunto representa menos del $5 \%$. En materia de importaciones, los datos son aún más contundentes: aquí China supera el $16 \%$ del total de bienes importados tanto por Brasil como por Argentina, y quién le sigue, la ASEAN en ambos casos, no alcanza el $4 \%$.

Gráfico 1: Porcentaje de exportaciones de Argentina y Brasil al espacio Asia-Pacífico

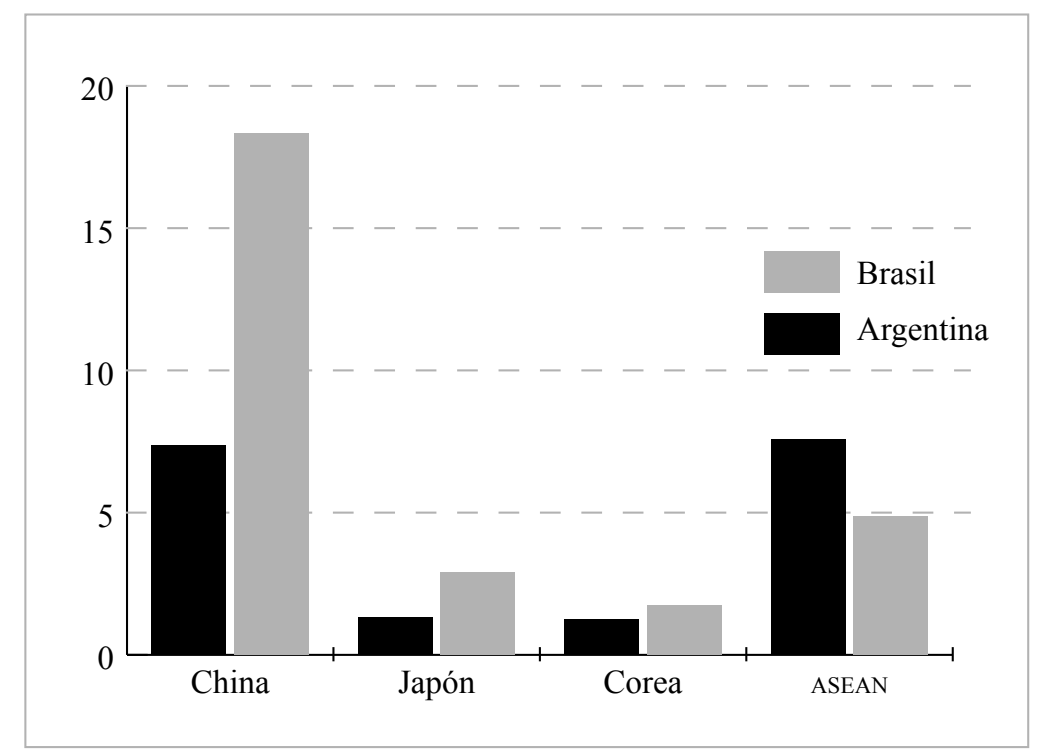

Fuente: elaboración propia.

5 Brunei, Camboya, Filipinas, Indonesia, Laos, Malasia, Birmania, Singapur, Tailandia y Vietnam. 
Gráfico 2: Porcentaje de importaciones de Argentina y Brasil desde el espacio Asia-Pacífico

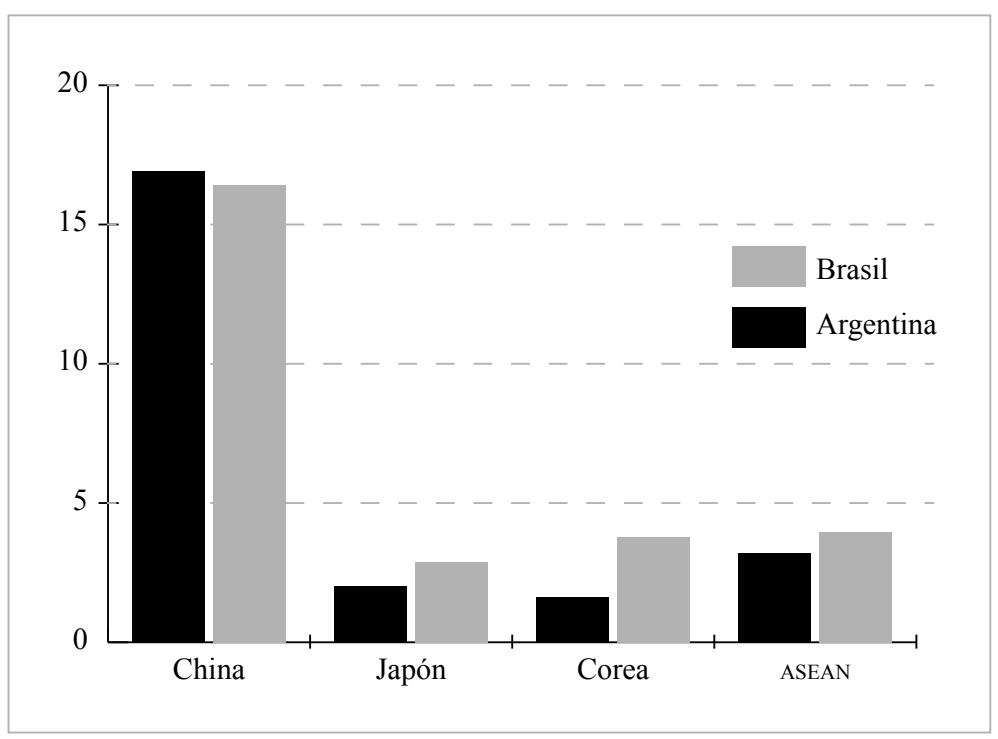

Fuente: elaboración propia.

Por tanto, al analizar la alternativa del giro hacia el Pacífico en el caso del Mercosur, con miras a considerar sus perspectivas, límites e implicancias, las estrategias convergen necesariamente —al menos si se pretende trabajar sobre una base real, independiente de las estrategias discursivas de los bloques regionales en la promoción de sus agendas - en el estudio de la relación económica con China. Este país ha experimentado un dinamismo económico sin precedentes, pasando a ser, como fuera mencionado, la segunda economía mundial y el mayor exportador del planeta en tan solo 35 años. Este cambio de profundas dimensiones ha reconfigurado el funcionamiento de la economía internacional, y los países del Mercosur no han estado exentos de sus efectos.

Dentro de estos se destaca el ya referido boom de las commodities, propulsado por la demanda china y con amplias implicancias para los exportadores de bienes intensivos en recursos naturales, como los países de la región. En efecto, las exportaciones hacia China de Argentina y, principalmente, de Brasil, han aumentado en forma sustantiva, como lo muestra el gráfico 3. En el caso de Brasil, se observa un incremento exponencial entre 2000 y 2011, un pico máximo en 2013 y una posterior leve caída, que de todos modos no altera el hecho de que estamos frente a valores muy elevados en perspectiva histórica. Argentina, por su parte, también experimenta un crecimiento en sus exportaciones a China entre $2000 \mathrm{y}$ 2016, aunque mucho menor comparado con el caso brasileño. 
Gráfico 3: Evolución de las exportaciones de Argentina y Brasil hacia China

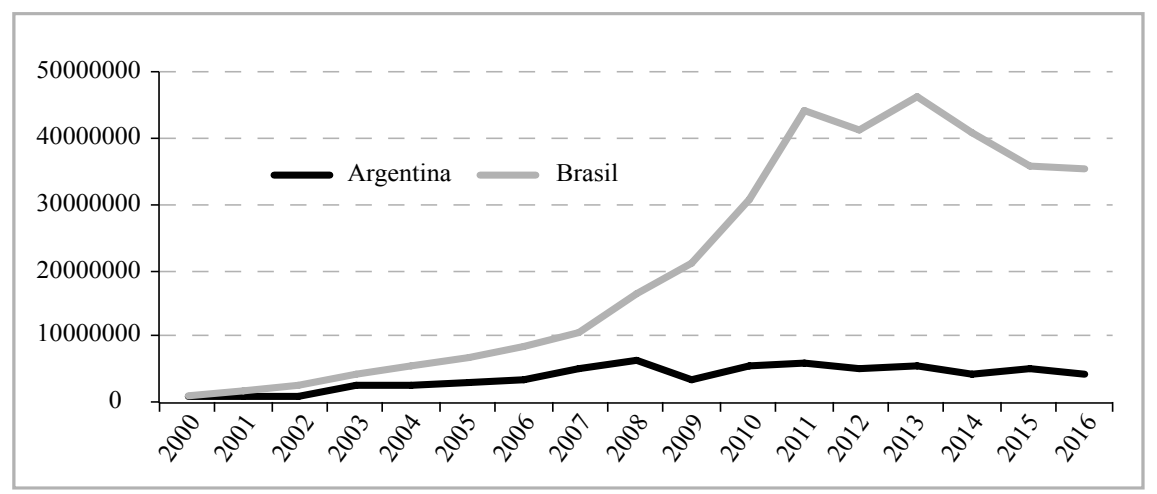

Fuente: elaboración propia.

Un segundo elemento para visualizar la importancia de China en la inserción de los productos argentinos y brasileros en los mercados externos viene dado por la evolución del peso de China en el total de las exportaciones de ambos países. El gráfico 4 presenta esta información. Allí se destaca en particular el aumento de la relevancia de China para las exportaciones brasileñas, que pasa de tan solo el $2 \%$ en el año 2000 a alcanzar un $19 \%$ en 2016, configurándose así en el principal destino de exportación de los productos brasileños. Esto muestra además que el descenso en los valores a partir de 2013, visto en el gráfico previo, no se debe a un retroceso de China como destino, sino a una contracción general de las exportaciones brasileñas.

Gráfico 4: Evolución porcentual de la participación de China en las exportaciones de Argentina y Brasil

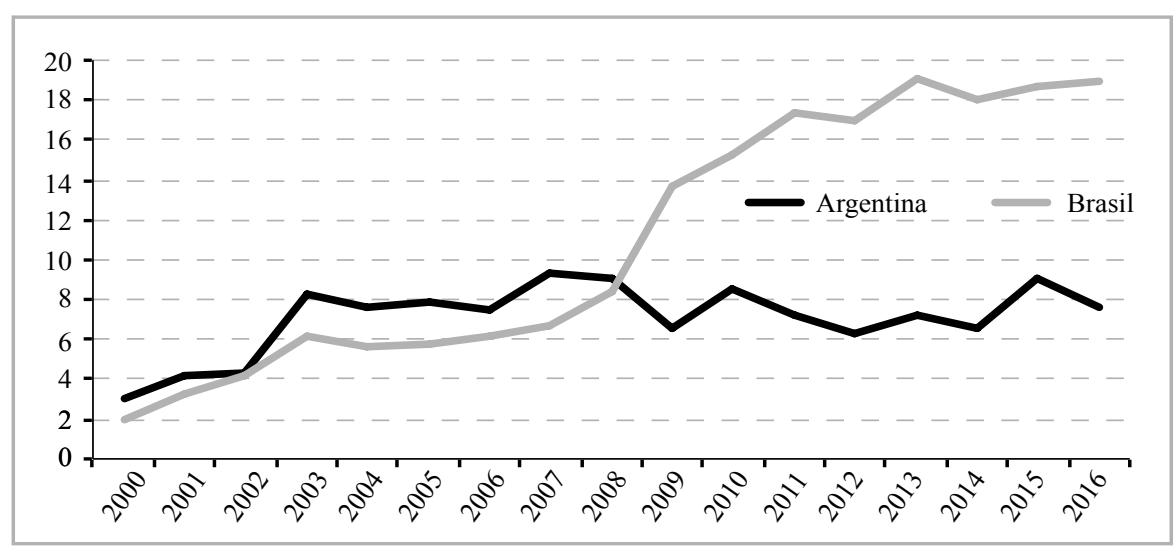

Fuente: elaboración propia. 
En el caso de Argentina, se observa un peso más moderado, no obstante significativo y de mayor relevancia en comparación con los valores registrados a inicios de los 2000, es decir, antes del boom de las commodities. Así, China se ha consolidado como el tercer destino de las exportaciones de Argentina, lejos de Brasil pero muy cerca de su segundo comprador, Estados Unidos.

Además de ilustrar estas tendencias generales, es importante identificar los sectores que explican este crecimiento. En este sentido, la literatura ha identificado que tan solo 10 productos representan el $75 \%$ del total de las exportaciones de América Latina a China: crudo de petróleo, minerales, soja y otras semillas, hierro, cobre, aceite de soja, residuos de metales no ferrosos, pulpa y desechos de papel, alimento para ganado, y carne (Gallagher y Porzecanski, 2010, p. 18). Brasil es el primer exportador latinoamericano en cuatro de estos sectores (soja, minerales, pulpa y desechos de papel, y carne) y el segundo en crudo de petróleo; mientras que Argentina lidera en crudo de petróleo y aceite de soja, y secunda a Brasil en soja (ídem). En otras palabras, los bienes intensivos en recursos naturales son aquellos que explican el exponencial crecimiento de las exportaciones de las principales economías del Cono Sur a China.

Repasadas las tendencias en exportaciones, cabe analizar la evolución de las importaciones argentinas y brasileñas desde China. De nuevo, se destaca en particular la penetración de las importaciones chinas en Brasil, con dos períodos de claro crecimiento (2003-2008 y 2010-2014), tras el que se observa una sensible reversión - producto de la recesión en Brasil — que no obstante mantiene los valores en niveles altamente elevados en una perspectiva histórica. El caso de Argentina muestra nuevamente una mayor moderación y menos sobresaltos; sin embargo, refleja un importante crecimiento de las exportaciones chinas hacia dicho país.

Gráfico 5: Evolución de las importaciones de Argentina y Brasil desde China

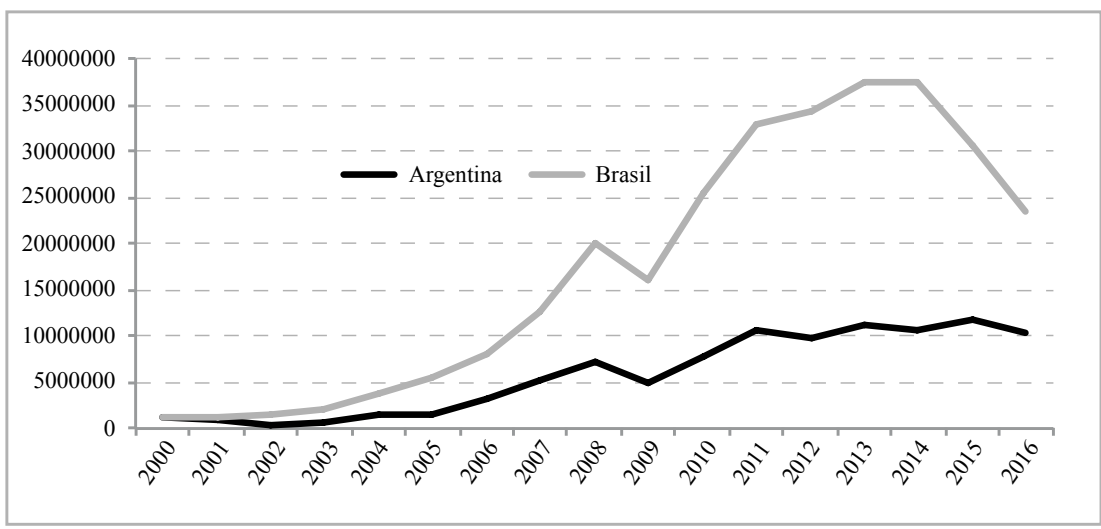

Fuente: elaboración propia. 
El peso de China en el total de las importaciones de Argentina y Brasil reafirma la importancia creciente de este país. En concreto, en ambos casos los valores pasan de menos del $5 \%$ en el 2000 a representar alrededor del $15 \%$ y $20 \%$, respectivamente, en los últimos años. Además, China es el segundo origen de las importaciones de Argentina y de Brasil, por detrás del propio Brasil en el primer caso y de Estados Unidos en el segundo. A su vez, y a diferencia del crecimiento de las exportaciones de los países sudamericanos hacia China, la penetración de China en Argentina y Brasil se basa en la venta de una amplia variedad de productos manufacturados (Gallagher y Porzecanski, 2010).

Gráfico 6: Evolución porcentual de la participación de China en las importaciones de Argentina y Brasil

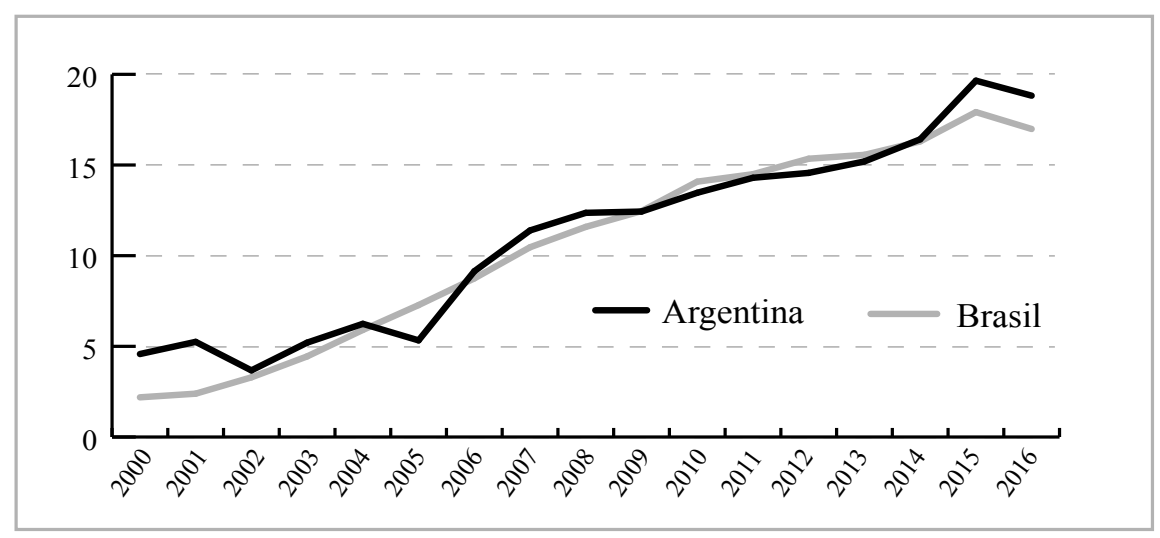

Fuente: elaboración propia.

Este aspecto no solo es importante por las externalidades positivas asociadas a una inserción en estos segmentos del mercado, sino porque además supone una creciente competencia para las exportaciones manufactureras de los países latinoamericanos. De hecho, Gallagher y Porzecanski (2010) encuentran que el $91 \%$ y $96 \%$ de las exportaciones de manufacturas de Brasil y Argentina, respectivamente, se encuentran bajo amenaza directa o parcial de la competencia china. Esto es particularmente relevante para el comercio intrarregional, que se destaca por contener mayores niveles de intercambio de productos manufacturados que aquellos que ocurren con el resto del mundo. El gráfico 7 muestra una tendencia que sugiere, si bien no confirma, que las exportaciones de productos manufacturados desde China hacia Argentina podrían estar desplazando a las manufacturas exportadas desde Brasil a su vecino. Y, además, señalan la necesidad de avanzar en mayor medida en el análisis de la competencia china en los propios mercados domésticos de estos países. 
Gráfico 7: Evolución de la participación de las importaciones de productos manufacturados de Argentina, desde Brasil y China

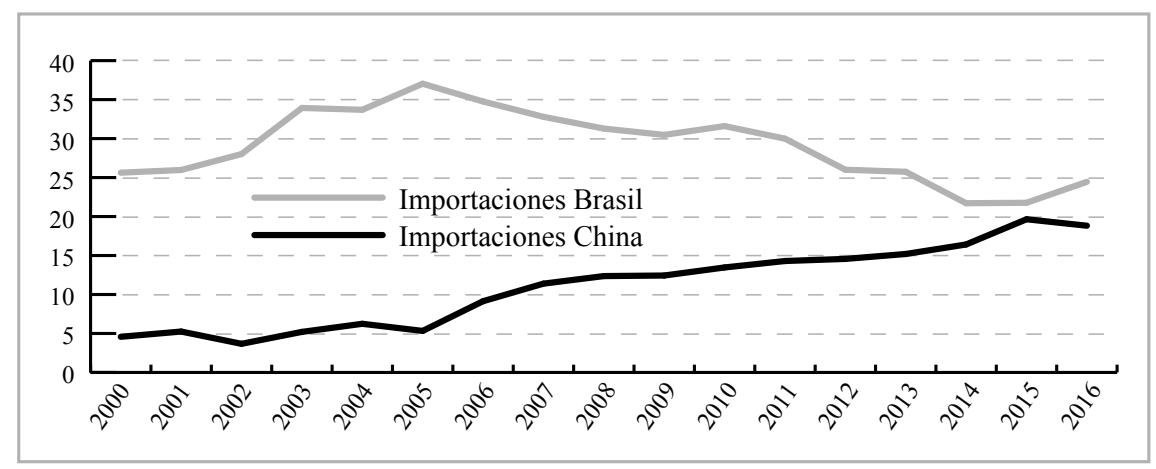

Fuente: elaboración propia.

Estas transformaciones son relevantes en tanto tienen el potencial de generar realineamientos políticos que influyan en las decisiones de política exterior económica de los países. En particular, los cambios en las tendencias comerciales asociadas al ascenso de China han tendido a fortalecer a los sectores exportadores de productos primarios en la región, quienes se han beneficiado del aumento de los volúmenes y precios de sus productos. Y, en cambio, han tendido a disminuir la fortaleza de los sectores industriales, quienes no solo no logran insertarse en China, sino que enfrentan una competencia creciente de este país en los mercados regionales y en sus propios mercados domésticos, a pesar de unos niveles comparativamente elevados de protección establecidos a nivel del arancel externo común del Mercosur.

No obstante, una eventual inserción basada en el privilegio de las relaciones comerciales con China, pensada exclusivamente a partir de la búsqueda de ganancias de la especialización en los sectores con ventajas comparativas, enfrenta restricciones en diversos planos. Una de ellas es que la dependencia de la evolución de los precios de los commodities supone una fuente de vulnerabilidad e inestabilidad para la gestión de la macroeconomía y para las perspectivas de desarrollo. Otra es que los sectores primarios no tienen la capacidad de absorber el excedente de demanda laboral de Argentina y Brasil, lo que sostenido en el tiempo, y plasmado en altos niveles de desempleo o empleo informal, puede generar problemas de estabilidad social. Frente a esto la teoría económica sugeriría que compensando a los perdedores, mediante mecanismos como la redistribución vía impuestos, todos los sectores podrían mejorar su situación; sin embargo, esta solución no ofrece perspectivas de realización política en tanto los sectores ganadores acumulan capital político y económico que eventualmente utilizarán para rechazar medidas que afecten negativamente sus ingresos. 
Por todos estos motivos es que entra a tallar el rol del Estado y de la política. En países como Brasil, la apertura hacia China desafía no solo los proyectos industriales de ciertos sectores del Estado, sino que también pone en cuestión el liderazgo de las empresas manufactureras brasileñas en importantes segmentos del mercado del Mercosur. Además, interpela las diferentes ideas que conviven en el Estado brasileño con respecto al modelo de desarrollo, en particular el debate entre los sectores más liberales que plantean priorizar las ventajas comparativas actuales en los mercados mundiales y los sectores nacionalistas y de izquierdas que buscan el desarrollo de capacidades industriales autónomas. Aquí se evidencia a su vez una paradoja, en tanto políticamente los sectores nacionalistas y de izquierdas buscan alianzas sur-sur y la conformación de un orden multipolar a través de los BRICS, mientras resisten el avance económico de China; los sectores más liberales priorizan a Estados Unidos y Europa en términos políticos pero promueven la apertura hacia el pacífico en lo económico.

Mientras que en Argentina, además del desafío que supone la penetración de China en Brasil, principal mercado de exportación argentino, se manifiesta la necesidad de gestionar el conflicto campo-ciudad que cruza a la economía política de ese país, combinando un margen de apertura para el desarrollo agro-exportador (no solo para la soja, ya consolidada en el mercado chino, sino para la carne, con una llamativa escasa presencia hasta el momento), con el mantenimiento de iniciativas industriales que emplean a buena parte de los sectores medios-bajos y medios del país, lo que asegura cierta estabilidad social. Y lo que es más, se teme un comercio irrestricto con un país con el que se sostiene un abultado déficit de balanza comercial desde hace una década. Tal vez por ello no sorprende que las administraciones de diferente signo político $-\mathrm{y}$ respaldadas por distintas coaliciones socioeconómicas - se hayan mostrado reticentes a la idea de un acuerdo de comercio preferencial entre el Mercosur y China. En conclusión, la alternativa del Pacífico centrada en China se apoya en una coalición fortalecida por fenómenos económicos recientes, pero también limitada por consideraciones geopolíticas, materiales e ideacionales.

\subsection{Límites geoeconómicos y de economía política en la alternativa atlántica}

Las negociaciones UE-Mercosur parecen encontrarse en este momento en una (larga) etapa de potenciales definiciones, luego de haber pasado distintos momentos. El inicio de las negociaciones a los efectos de concretar un Acuerdo Marco, en el año 1995, fue la primera decisión del Mercosur como sujeto de derecho internacional. Esto no fue casual, teniendo en cuenta la posición atlántica de los países del bloque sudamericano y la referencia en términos de ideas e instituciones que supuso el modelo europeo para sus creadores (Bizzozero, 2008). A 
su vez, significó en ese momento un cambio en las relaciones interregionales, en la construcción de gobernabilidad y en las negociaciones en el marco del sistema de comercio mundial. Durante varios años, no obstante, las negociaciones estuvieron estancadas, tanto por el traslado de las cuestiones comerciales a la esfera multilateral como por desavenencias y diferencias en las prioridades de ambos bloques, hasta que se retomaron hacia fines de la primera década del siglo XXI. Sin embargo, aún no han concluido, y una de las razones fundamentales obedece al patrón de comercio entre ambas regiones.

En términos de evolución del comercio, y a diferencia del caso de China, los valores de las exportaciones de Brasil y Argentina hacia los países de la UE en las últimas décadas muestran tendencias más inconsistentes, como ilustra el gráfico 8. En el caso de Brasil se observa un marcado incremento en las exportaciones hacia la UE entre 2002 y 2008, luego un pico en 2011, pero tras esto una importante caída que hace que en 2016 se registren valores similares a los registrados diez años atrás, en 2006. Mientras que Argentina muestra un leve incremento en sus ventas al mercado europeo entre 2001 y 2008 , tras lo que se suceden fluctuaciones que no obstante revelan una tendencia descendente.

Gráfico 8: Evolución de las exportaciones de Argentina y Brasil hacia la UE

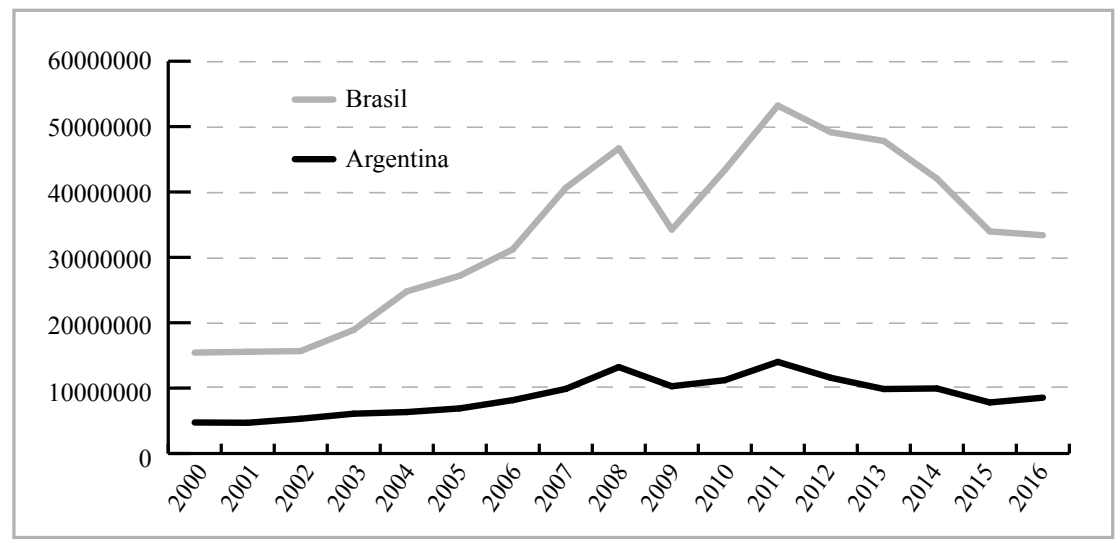

Fuente: elaboración propia.

Sin embargo, los datos más ilustrativos emergen al analizar la evolución del peso de la UE en el total de las exportaciones de estos países del Mercosur, lo que se presenta en el gráfico 9. El caso de Brasil es el más relevador al respecto. En el 2000, casi el $30 \%$ de las exportaciones brasileñas se dirigían hacía el bloque europeo; en 2016 ese valor había caído a menos del $20 \%$. Cierto es que considerada 
en conjunto, la UE es aún el principal destino para los productos brasileros, pero la distancia con China es de decimales, e incluso si estos valores se congelaran en el tiempo, China sobrepasaría a la UE tan solo por el efecto de la salida del Reino Unido del acuerdo comunitario. El caso de Argentina, de forma similar, muestra una tendencia decreciente, revelando una caída de la importancia de la UE como destino de exportación para las principales economías del Mercosur.

Gráfico 9: Porcentaje de participación de la UE en las exportaciones de Argentina y Brasil

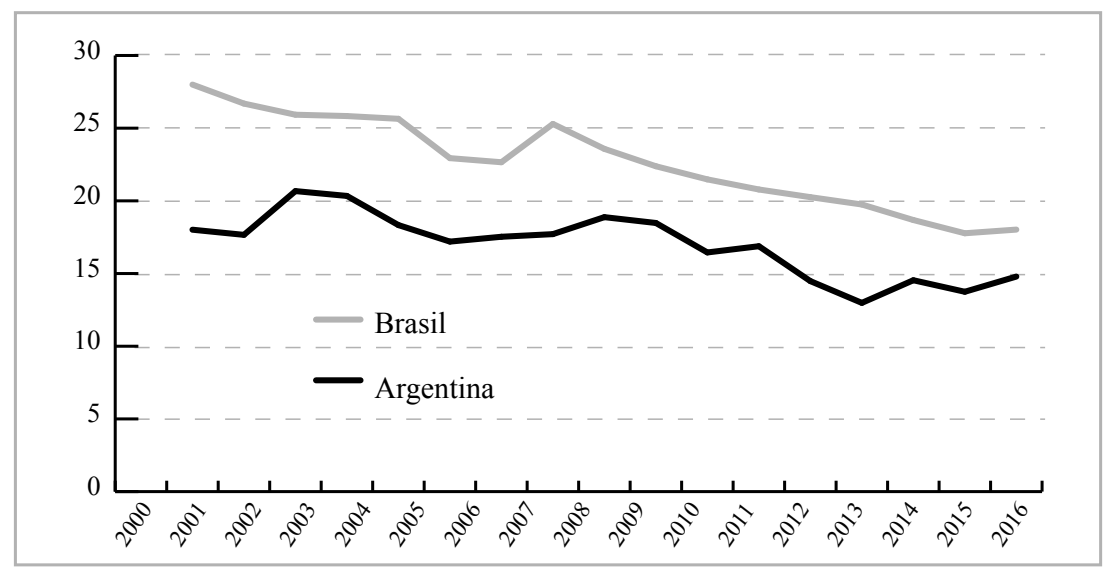

Fuente: elaboración propia.

En líneas generales, como refleja el gráfico 10, la evolución de las importaciones de Argentina y Brasil desde la UE ha seguido un patrón similar al de las exportaciones hacia este bloque. Brasil incrementó sus compras desde la UE de forma sostenida desde 2003 a 2008, y tras una caída producto de la crisis económica global alcanzó un pico máximo en 2013. Sin embargo, en 2016, en medio de la recesión brasileña, los valores totales fueron similares a los de 2008. Las importaciones desde Argentina muestran una evolución más moderada, con una tendencia apenas creciente, que de todos modos repite valores cercanos en 2008 y 2016 al igual que Brasil. 
Gráfico 10: Evolución de las importaciones de Argentina y Brasil desde la UE

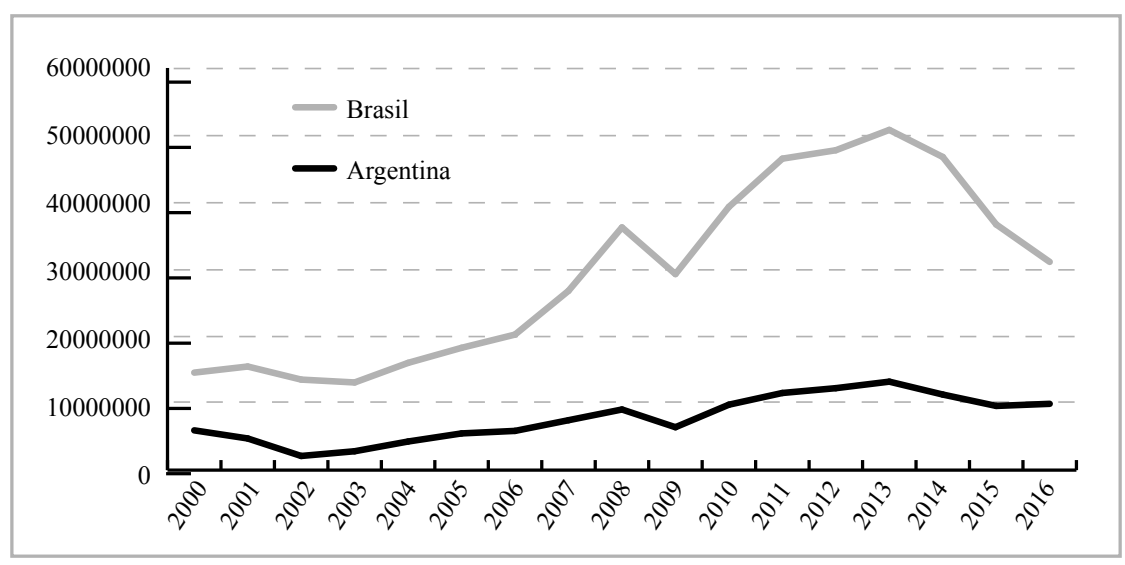

Fuente: elaboración propia.

El peso de las importaciones desde la UE, tal como muestra el gráfico 11, ha seguido un patrón similar para ambos países. En particular, se observa una tendencia claramente decreciente entre 2002 y 2011, en donde la UE pierde alrededor de 8 puntos porcentuales en cada país. Esta caída significativa evidencia una pérdida de competitividad de las exportaciones europeas frente a otros centros mundiales de exportación, en particular Asia. Desde 2011 hasta la actualidad se vislumbra en cambio una incipiente recuperación de la participación europea en los mercados argentino y brasileño, aunque muy leve: de hecho, en estos 5 años la UE ha recuperado tan solo dos puntos de los ocho perdidos entre 2002 y 2011.

Gráfico 11: Evolución de la participación en las importaciones de Argentina y Brasil desde la UE

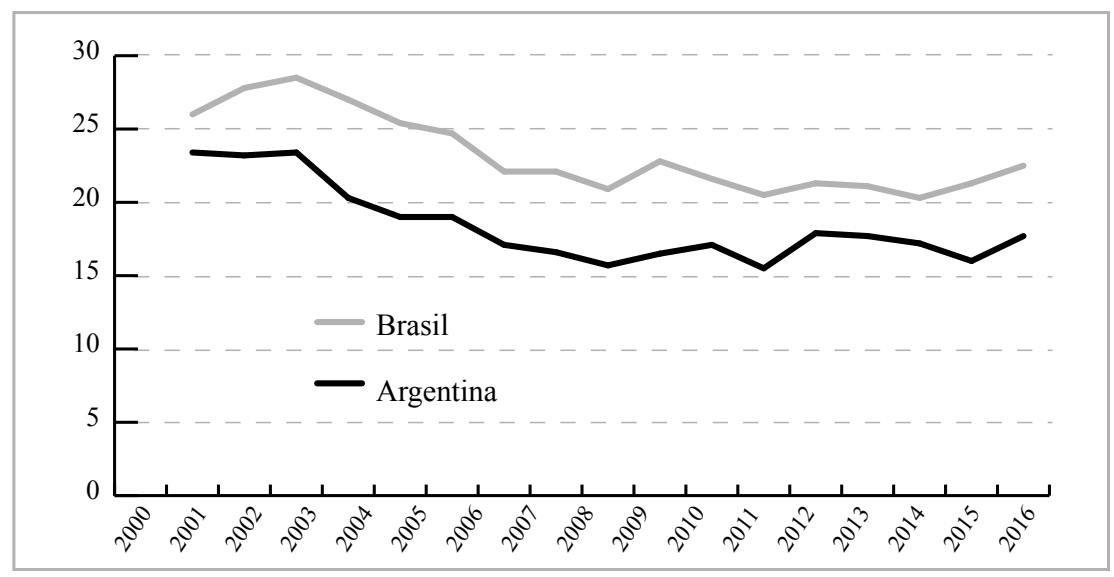

Fuente: elaboración propia. 
En cuanto a la composición del comercio, tanto Argentina como Brasil concentran su canasta exportadora hacia la UE en productos primarios: en 2016 el $65 \%$ de las exportaciones argentinas fueron productos alimenticios y animales vivos, seguidas de materiales crudos no comestibles, excepto combustibles (16\%); mientras que en el caso de Brasil las principales ventas fueron productos alimenticios, bebidas y productos de tabaco (18,2\%), productos vegetales $(17,9 \%)$ y productos minerales $(16,3 \%)$. En cambio, las exportaciones de la UE a los dos países sudamericanos se concentran en productos manufacturados: maquinaria y equipos de transporte $(50 \%)$ y productos químicos $(22 \%)$ representan el grueso de las exportaciones de la UE hacia Argentina; y maquinaria y accesorios $(25,7 \%)$, productos químicos $(24,4 \%)$ y equipos de transporte $(18,1 \%)$ componen los principales productos de la canasta dirigida hacia Brasil. El saldo de balanza comercial es favorable para la UE en los dos casos (Comisión Europea, $2017 a ; 2017 b)$.

Frente a esta realidad es que se presenta la alternativa de una inserción atlántica, centrada en la posibilidad de un acuerdo de comercio preferencial entre la UE y el Mercosur. Para los sectores exportadores de productos primarios en el Cono Sur, principalmente los agroexportadores, un eventual acuerdo puede generar la expectativa de recuperar espacio en el mercado europeo mediante la obtención de preferencias arancelarias, en un mercado altamente protegido por barreras de diverso tipo. En cambio, no se vislumbra en la actualidad como una herramienta para mejorar la inserción de productos manufacturados en competencia con terceros países como la propia China, pues ello requeriría una apuesta productiva que va más allá de los efectos que puede generar un acuerdo de preferencias comerciales.

Para la UE, en cambio, el acuerdo con el Mercosur sí representa una oportunidad de retomar impulso en los mercados de manufacturas argentino y brasileño frente a la creciente competencia de China y Asia en general. Esto se debe a que ambos países imponen aranceles relativamente elevados para el contexto internacional (por encima del $10 \%$ ), por lo que un acuerdo preferencial daría un margen de ventaja importante a los productos europeos. ${ }^{6}$ Además, la UE busca acceder a los mercados de contrataciones públicas argentino y brasileño, otro sector relativamente protegido y de dividendos potencialmente elevados.

6 De todos modos, esto en ningún caso aseguraría la prevalencia de Europa en el Cono Sur. Nótese por ejemplo la penetración de las exportaciones chinas en Estados Unidos a costa de México (Gallagher y Porzecanski, 2010), la que ha ocurrido a pesar de las preferencias arancelarias disfrutadas por México en el marco del NAFTA. En otras palabras, el otorgamiento de preferencias debe ser visto como un elemento más en el resultado final de las tendencias comerciales, pero de ningún modo como la receta mágica a los problemas de competitividad que enfrentan los países de la región, como en ocasiones sugieren algunos análisis académicos y de prensa. 
De forma importante, un acuerdo comercial con la UE puede generar menos resistencias en los debilitados industriales brasileños y argentinos que un acuerdo similar con China, producto de que la participación de las manufacturas europeas en sus mercados nacionales es de más larga data (por lo que ya ha sido internalizada por los actores locales) y a la vez se encuentra en relativo declive. ${ }^{7} \mathrm{~A}$ su vez, si la uE no presiona en demasía en los capítulos relacionados con el comercio como propiedad intelectual y compras públicas (donde podría acordarse un mínimo elevado y sujeto a condiciones de coparticipación con empresas locales), la oposición de las visiones neodesarrollistas en los estados sudamericanos tendría menos peso o, al menos, tendería a ver el acuerdo como una concesión menor frente a la opción de una apertura hacia Asia. Dicho esto, los eventuales costos asociados a la pérdida de espacio para políticas en el Mercosur, que producto de las recesiones en sus principales economías, presiones competitivas y falta de alternativas llega a la mesa en una posición negociadora débil, no deben subestimarse. Y si a esto se le suma la falta de acuerdos vigentes intra-Mercosur, producto del problema de internalización reseñado anteriormente $\mathrm{y}$, por tanto, la ausencia de una política común se encuentra que la debilidad en las negociaciones sobre estos temas puede ser incluso mayor.

De todos modos, una oferta europea como la actual, altamente restrictiva en sectores agroexportadores claves - como la carne y el etanol- significa la ausencia de una coalición promotora del acuerdo que contrapese a los sectores reticentes a la apertura en el Mercosur. Y, de forma crucial, esta oferta restrictiva es producto de condicionantes de economía política estructurales del lado europeo, en donde la protección de la agricultura es un elemento constitutivo del propio bloque - al punto que la política agraria común de la Comisión es la mayor receptora individual de los fondos comunitarios - (Heydon, 2012), y un compromiso central dentro de los equilibrios domésticos de países centrales como Francia. Así, con un margen de acción europeo acotado, las posibilidades de negociar ofertas sustanciosas que generen apoyos políticos importantes entre los actores con intereses ofensivos en el Mercosur se ven comprometidas.

En definitiva, si bien la alternativa atlántica presenta un balance más favorable para su concreción en la ecuación de intereses e ideas de la economía política internacional de los países del Mercosur, al mismo tiempo choca con tensiones estructurales que se vienen reproduciendo desde el lanzamiento de las negociaciones en 1995, con el agregado de que reaparecen en un nuevo contexto de intercambios declinantes y de desplazamiento del motor económico internacional

7 Aunque algunos sectores, como el automotriz, construido a partir de los incentivos a la inversión extranjera directa horizontal producidos por elevadas barreras arancelarias, han planteado su oposición. 
en dirección a Asia. Y por tanto, se enfrenta a un conjunto de tensiones y desafíos que ponen en duda su viabilidad como estrategia para el nuevo impulso de inserción que busca adoptar el Mercosur.

\section{Reflexiones finales}

Los cambios de gobierno en Argentina y Brasil han traído un nuevo impulso a la agenda externa del Mercosur, y como contracara han supuesto el repliegue de la agenda de construcción de instituciones políticas regionales. Esto presume un nuevo escenario para el regionalismo en América del Sur, aún no del todo definido, y no puede entenderse sin referir tanto a elementos político coyunturales como a transformaciones estructurales de más largo aliento. Y es que los cambios producidos a nivel de la economía política internacional, con el ascenso de China como epicentro, significaron en el corto plazo la posibilidad de ampliar las esferas de acción autónoma, sustentada en los nuevos recursos derivados del boom de las commodities y la ampliación de las oportunidades de financiamiento internacional. Sin embargo, en el mediano plazo, estos mismos fenómenos empoderaron a los sectores productivos poseedores de las ventajas comparativas tradicionales, quienes tienen por su especialización una preferencia por políticas ortodoxas de liberalización y acceso a mercados y, al mismo tiempo, llevaron a una reconsideración paradigmática en los sectores industriales que han enfrentado una creciente competencia en los mercados de manufacturas interno y regionales.

Como consecuencia, hoy el bloque regional se reorienta hacia la búsqueda de opciones de inserción externa, entre las que se destacan las alternativas Pacífica y Atlántica. Sin embargo, como se ha visto, ambas enfrentan importantes limitantes y desafíos. La primera, que a nivel regional se ha construido en torno a la Alianza del Pacífico, interpela el carácter atlantista de los países del Mercosur. Al mismo tiempo, presenta un modelo ideacional alineado con los cambios políticos recientes en Argentina y Brasil, pero que genera fricciones en los segmentos neodesarrollistas de las burocracias, especialmente en Brasil. De todos modos, enfocarse en el Pacífico para los países del Mercosur supone básicamente negociar con China, y estas eventuales negociaciones pueden correr por carriles independientes a la Alianza sin ningún inconveniente.

La alternativa Pacífica tiene el potencial de redituar importantes ganancias para las exportaciones tradicionales de los países del Mercosur a los mercados mundiales, que han visto crecer el peso de China entre los compradores externos, en especial para el caso de Brasil, y con oportunidades aún no concretadas para el caso argentino. Esto se debe a que la eliminación de las barreras arancelarias que enfrentan estas exportaciones mejoraría su rentabilidad y las volvería aún 
más competitivas. Sin embargo, como contracara, afectaría fuertemente a los ya tensionados sectores industriales. Y de forma concomitante, una especialización productiva muy marcada en las exportaciones tradicionales enfrentaría desafíos en materia de inestabilidad macroeconómica asociada a la fluctuación de precios, la absorción de la mano de obra (desempleo) y la falta de condiciones políticas para generar estrategias distributivas que compensen a los perdedores. Así las cosas, no sorprende la reticencia frente a la alternativa china incluso de los nuevos gobiernos, de orientación más liberal, en ambos países.

En cambio, la alternativa Atlántica reafirma la orientación geopolítica tradicional de los países del Mercosur, lo que supone menos desafíos, y mantiene su atractivo para los sectores exportadores tradicionales, en tanto la UE cuenta con un mercado agrícola altamente protegido y con una renta per cápita sensiblemente mayor que China, lo que redunda en mayores precios. Y además, de forma central, resulta una opción menos amenazante para los sectores industriales, pues ya tienen internalizada la presencia europea y dicha presencia muestra, a su vez, una tendencia declinante. Sin embargo, la incapacidad europea de generar una oferta atractiva en agricultura lleva a la falta de una coalición promotora fuerte desde el lado sudamericano. Y nótese que dicha incapacidad es estructural, al punto que no ha variado siquiera en un momento en que, producto de las tensiones transatlánticas tras la victoria de Donald Trump en Estados Unidos, la UE busca consolidarse como el faro de referencia del libre comercio en Occidente.

El Mercosur cuenta con espacio para ofrecer concesiones en aspectos relacionados, y dada su posición de debilidad negociadora relativa parece dispuesto a hacerlo incluso sin grandes ganancias en agricultura como contrapartida, sino tan solo como señal de apertura al mundo. Desde una perspectiva liberal esto podría suponer ganancias de eficiencia en, por ejemplo, compras públicas y servicios, ${ }^{8}$ aunque no así en todos los capítulos, pues la protección de indicaciones geográficas que usualmente demanda la UE reduce de hecho la competencia y encarece los productos en los mercados de bienes. Y desde una perspectiva neodesarrollista, preocupada por la pérdida de espacio para políticas de desarrollo, las concesiones sin contrapartidas simplemente no tendrían sentido. Así, se concluye que a pesar del nuevo impulso puesto en la orientación externa del Mercosur, las principales alternativas muestran una serie de limitantes geopolíticos y de economía política cuya superación no es para nada evidente.

8 Aunque estudios empíricos cuestionan estas ganancias en servicios, ej. Manger (2008). 


\section{Referencias}

ARnOld, C. (2017). Empty promises and nonincorporation in Mercosur. International Interactions, 43(4), 643-667.

BAn, C. (2016). Ruling Ideas: How Neoliberalism Goes Local. Oxford, Reino Unido: Oxford University Press.

Bizzozero, L. (2008). Uruguay en la creación del Mercosur. Montevideo, Uruguay: CSIC.

Bizzozero, L. (2014). La política exterior de Brasil hacia América Latina: del regionalismo abierto al continental. En R. Bernal-Meza, y L. Bizzozero (Eds.), La política internacional de Brasil: de la región al mundo (pp. 57-78). Montevideo, Uruguay: Cruz del Sur.

Bizzozero, L. (2015). Las elecciones en Chile, Bolivia, Brasil y Uruguay: debates sobre inserción internacional y convergencia regional. Densidades, 17, 69-85.

Bizzozero, L. y Raggio, A. (2016). El impacto de la República Popular China en el eje Argentina- Brasil entre el 2004 y el 2014. ¿Evolución sistémica-estructural o definiciones político-estratégicas? Araucaria. Revista Iberoamericana de Filosofia, Política y Humanidades, 35(1), 341-364.

Blyth, M. (2003). Structures Do Not Come with an Instruction Sheet: Interests, Ideas, and Progress in Political Science. Perspectives on Politics, 1(4), 695-706.

BouzAs, R. (1996). La agenda económica del Mercosur: desafíos de política a corto y mediano plazo. Integración \& Comercio, 1(0), 64-87.

BRICEÑo-Ruiz, J. (2013). Ejes y modelos en la etapa actual de la integración económica regional en América Latina. Estudios Internacionales, 175, 9-39.

Briceño-Ruiz, J. (2018). Times of Change in Latin American Regionalism. Contexto Internacional, 40(3), 573-594.

Briceño-Ruiz, J. y Morales, I. (2017). Post-Hegemonic Regionalism in the Americas. Nueva York, EE. UU.: Routledge.

Buxedas, M. (2017). ¿A dónde va la agricultura mundial? Oportunidades y desafíos para el Mercosur. En G. Caetano (Coord.), América Latina ante los desafíos de la globalización (pp. 279-296). Montevideo, Uruguay: Planeta.

Caetano, G. (2017). El futuro del proyecto Mercosur en los nuevos contextos. En G. Caetano (Coord.), América Latina ante los desafios de la globalización (pp. 353-387). Montevideo, Uruguay: Planeta. 
276 | Regionalismo, economía política y geopolítica

Chwieroth, J. (2007). Neoliberal Economists and Capital Account Liberalization in Emerging Markets. International Organization, 61(2), 443-463.

CNI (2014). Acordos Comerciais: Uma Agenda Para a Industria Brasileira, Brasilia: CNI. Recuperado de $<$ https://bit.ly/2H2SsJv>.

$\mathrm{C}_{\mathrm{NI}}$ (2017). Agenda Internacional da Industria 2017, Brasilia: CNI. Recuperado de $<$ https://bit.ly/2VKIUv0>.

Comisión Europea (2017a). Brazil. Trade Picture. Recuperado de <https://bit. ly/1TgS9bN>.

Comisión Europea (2017b). Argentina. Trade Picture. Recuperado de <https://bit. ly/2H4hDdp>.

DArós, L. (2017-sin edición). Brazilian Trade Policy: Explaining the Role of Interests and Ideas in the Recent Change in the Manufacturing Sector's Position Towards Trade Liberalization. LSE MSc Dissertation, Londres.

De Ville, F., y Siles-Brugge, G. (2018). The role of ideas in legitimating eu trade policy. En S. Khorana, y M. García (Eds.), Handbook on the EU and International Trade (pp. 243-262). Cheltenham, Reino Unido: Elgar.

Florian, L. (2014). Les grands théoriciens de la géopolitique. París, Francia: PUF.

Gallagher, K. (2007). Understanding Developing Country Resistance to the Doha Round. Review of International Political Economy, 15(1), 62-85.

Gallagher, K., y Porzecanski, R. (2010). The Dragon in the Room. China and the Future of Latin America Industrialization. Stanford, EE. UU.: Stanford University Press.

Gallagher, K.; Irwin, A. y Koleski, K. (2012). The New Banks in Town: Chinese Finance in Latin America. Report. Washington D.C. EE. UU.: Inter-American Dialogue.

GiacAlone, R. (2015). El orden regional sudamericano en la segunda década del siglo XXI ¿conflicto o negociación? En N. Mellado (Ed.), Estrategias de inserción internacional e integración latinoamericana en el siglo XXI (pp. 55-77). Córdoba, Argentina: Lerner.

GrAnd, J. (2000). Mercosur-TLCAN-UE: ¿triángulo atlántico o triángulo de las Bermudas? Civitas, 1(1), 97-122.

Hall, P. (1993). Policy Paradigms, Social Learning, and the State: The Case of Economic Policymaking in Britain. Comparative Politics, 25(3), 275-296. 
Hettne, B. (1994). The New Regionalism: Implications for Development. En B. Hettne, y A. Inotai (Eds.), The New Regionalism. Implications for Global Development and International Security (pp. 1-45). Helsinki, Finlandia: The United Nations University.

Heydon, K. (2012). The Political Economy of International Trade. En K. Heydon, y S. Woolcock (Eds). The Ashgate Research Companion to International Trade Policy (pp. 29-46). Farnham, Reino Unido: Ashgate Publishing.

LAKe, D. (2009). Open Economy Politics: A Critical Review. The Review of International Organizations, 4(3), 219-244.

LÓPEZ, C., y TARCiAnO Silva, R. (2015). El discurso político partidario sobre la política exterior en Brasil y Uruguay (2003-2014). Revista Uruguaya de Ciencia Política, 24(2), 67-85.

Manger, M.(2008). International Investment Agreements and Services Markets: Locking in Market Failure? World Development, 36(11), 2456-2469.

Mera, L. (2005). Explaining Mercosur's survival: Strategic sources of ArgentineBrazilian convergence. Journal of Latin American Studies, 37(1), 109-140.

Moïsı, D. (2008) La géopolitique de l'émotion. París, Francia: Flammarion.

Narlikar, A., y Tussie, D. (2004). The G20 at the Cancun Ministerial: Developing Countries and Their Evolving Coalitions. The World Economy, 27(7), 947966.

Pereira, C. (2011). América del Sur. El surgimiento de un actor global. En C. Díaz Barrado (Ed.), Monografías Sudamericanas. Madrid, España: CEIB-AECID.

Petersen, M., y Schulz, C. (2018). Setting the regional agenda: a critique of posthegemonic regionalism. Latin American Politics and Society, 60(1), 102-127.

Portes, R., y Rey, H. (1998), The Emergence of the Euro as an International Currency, NBER Working Paper n. ${ }^{\circ}$ 6424, National Bureau of Economic Research, Inc.

Riggirozzi, P., y Tussie, D. (2012). The Rise of Post-Hegemonic Regionalism. Londres, Reino Unido: Springer.

RoDrIK, D. (2014). When Ideas Trump Interests: Preferences, Worldviews, and Policy Innovations. Journal of Economic Perspectives, 28(1), 189-208.

SANAHuJA, J. (2009). Del regionalismo abierto al regionalismo posliberal. Crisis y cambio en la integración regional en América Latina y el Caribe. En L. Martínez, L. Peña, M. Vázquez (Coords.), Anuario de la integración de América Latina y el Gran Caribe no 7, 2008-2009 (pp. 11-54). Buenos Aires, Argentina: CRIES. 
Serbin, A. (2010). La agenda hemisférica y la administración Obama. En M. Mesa (Coord.) Balance de una década de paz y conflictos: tensiones y retos en el sistema internacional. Anuario 2010-2011 (pp. 227-252). Madrid, España: Ceipaz, Icaria.

SLIPAK, A. (2014). América Latina y China: ¿cooperación Sur-Sur o «Consenso de Beijing»? Nueva Sociedad, 250(2), 102-113.

Svampa, M. (2013). Consenso de los Commodities y lenguajes de valoración en América Latina. Nueva Sociedad, 244(2), 30-46.

Woll, C. (2008). Firm Interests: How Governments Shape Business Lobbying on Global Trade. Ithaca, EE. Uu.: Cornell University Press.

Los autores realizaron igual contribución para la realización del artículo. 